\title{
Images of the month 2: A leopard never changes its spots
}

\author{
Authors: James WL Denny, ${ }^{A}$ Sreedhar Krishna, ${ }^{B}$ Natasha Valiallah, ${ }^{C}$ Abigail Fogo ${ }^{B}$ and Janakan Natkunarajah ${ }^{B}$
}

KEYWORDS: Multiple lentigines syndrome, LEOPARD, Noonan, PTPN11

DOI: 10.7861/clinmed.2019-0489

\section{Case presentation}

A 34-year-old man with a background of hay-fever presented with hypopigmentation of the natal cleft, scrotum and penis. A diagnosis of vitiligo was provisionally made, but it was noted that he had a large number of freckles and exhibited facies in keeping with Noonan syndrome.

Examination revealed widespread lentigines which began appearing when the patient was 8 years old (Fig 1). He had a triangular-shaped face, low-set posteriorly rotated ears and widely-spaced bright blue eyes (Fig 2). Additionally, he was noted to have bilateral syndactyly of the second and third toes (Fig 3). His features were distinctly different from those of his direct and extended family. He was $185 \mathrm{~cm}$ tall and external genital examination was unremarkable. He was subsequently referred to clinical genetics, who detected a de novo defect in the protein tyrosine phosphatase non-receptor type 11 (PTPN11) gene mutation in keeping with multiple lentigines syndrome, previously known as LEOPARD syndrome. This alternative diagnostic designation is an apt acronym as characterised by the extensively 'spotted' clinical appearance but also of the signs noted in Table 1. Following his diagnosis, he was referred to cardiology and audiology. Electrocardiography, echocardiography and auditory analysis were all unremarkable.

Approximately 200 cases of multiple lentigines syndrome have been documented with approximately $90 \%$ exhibiting a PTPN11 mutation. ${ }^{1}$ In its inherited form, it is an autosomal dominant condition where cutaneous features commonly manifest in childhood. ${ }^{1}$ Although the acronym of clinical signs are commonly seen, it is extremely heterogeneous in both spectrum of disease

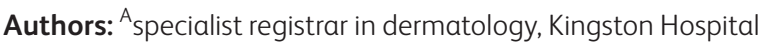
NHS Foundation Trust, Kingston upon Thames, UK; ${ }^{B}$ dermatology consultant, Kingston Hospital NHS Foundation Trust, Kingston upon Thames, UK; ${ }^{C}$ core medical trainee, Kingston Hospital NHS Foundation Trust, Kingston upon Thames, UK

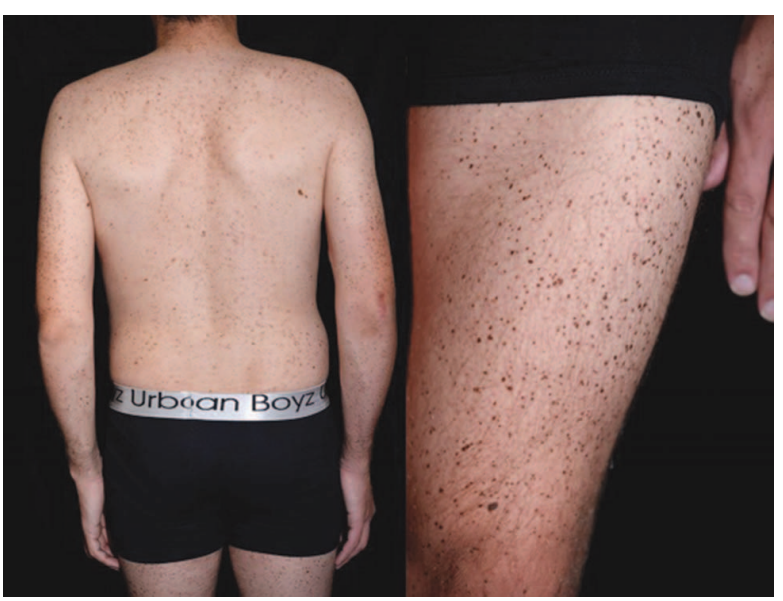

Fig 1. Multiple lentigines noted across the patient's body.

and severity. Diagnosis can be made without satisfying all components of the acronym as is the case with our patient who only demonstrated multiple lentigines and ocular hypertelorism.

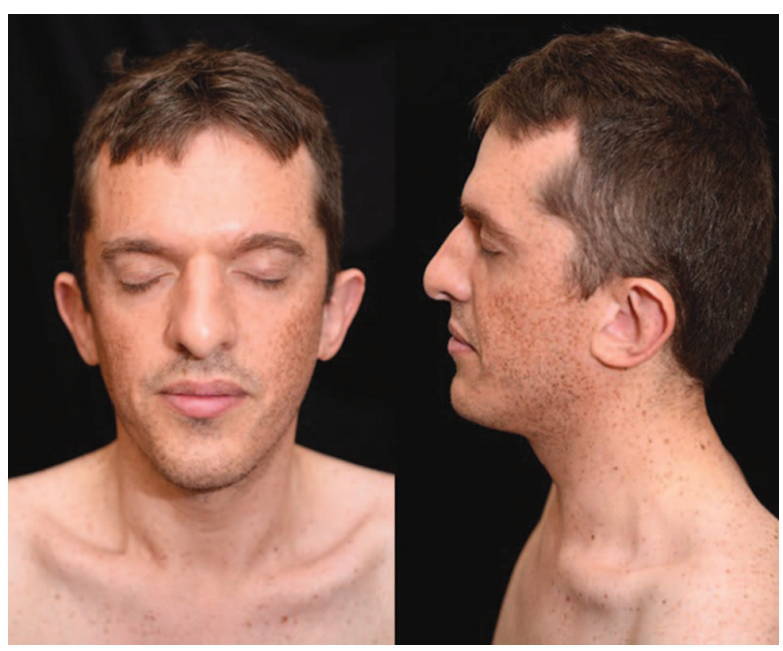

Fig 2. Multiple lentigines noted but also a triangular-shaped face plus low-set posteriorly rotated ears. 


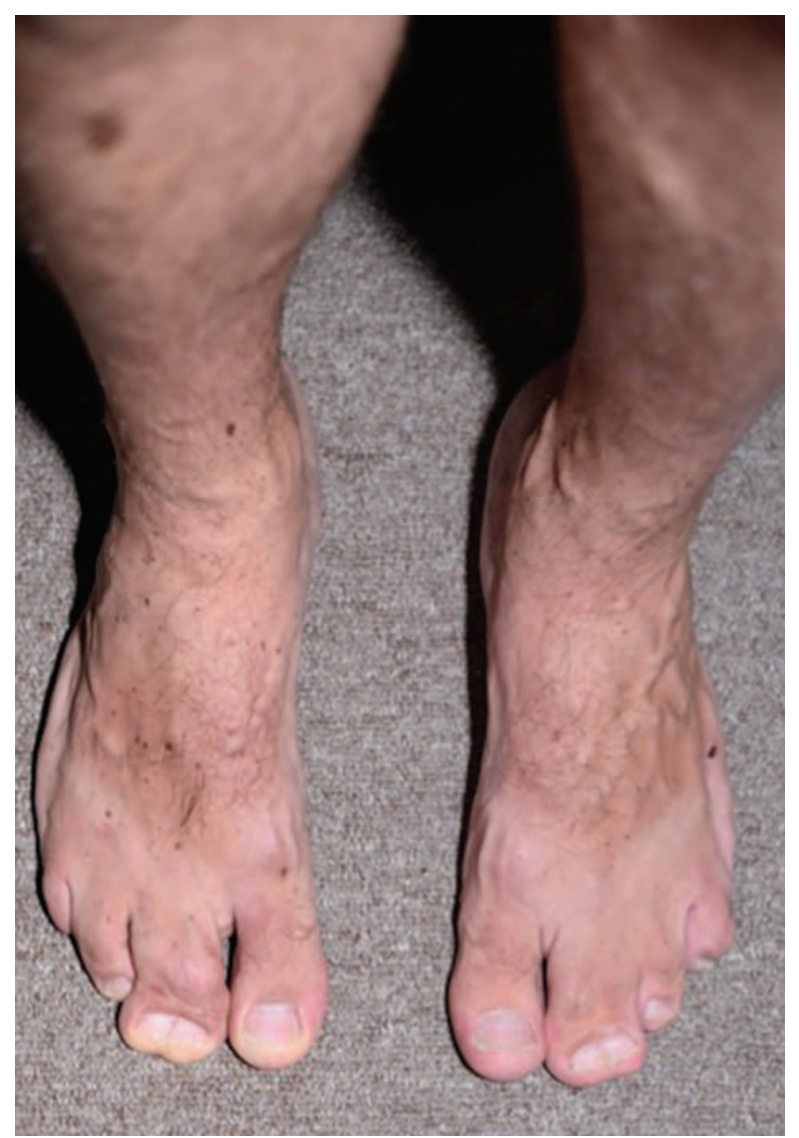

Fig 3. Bilateral syndactyly of the 2 nd and 3rd toes.

There are several other associations in the spectrum of this disease that fall outside of the confines of the acronym including syndactly, which our patient also demonstrated. ${ }^{2}$

PTPN11 is found at chromosomal position 12q24.13, of which to date 11 mutations have been identified as a cause of multiple lentigines syndrome. ${ }^{3}$ Most of these mutations result in a change in a single amino acid for the SHP-2 protein, disrupting its function. ${ }^{4}$ A decrease in SHP-2 function impairs the activation of the ras/mitogen-activated protein kinase signalling pathway, which controls cell functions such as growth and division but also melanin synthesis in melanocytes. ${ }^{3}$ This dysregulation can result in these various features of LEOPARD syndrome and is thus

Table
1. The distinct signs that make-up the
acronym and possible phenotype of LEOPARD
syndrome
$\begin{array}{ll}\text { 1 } \\ \text { L } & \text { Lentigines (multiple) } \\ \text { E } & \text { Electrocardiographic abnormalities } \\ \text { O } & \text { Ocular hypertelorism } \\ \text { P } & \text { Pulmonary stenosis } \\ \text { A } & \text { Abnormalities (genital) } \\ \text { R } & \text { Retarded growth (short stature) } \\ \text { D } & \text { Deafness (sensorineural) }\end{array}$

a rasopathy. ${ }^{3}$ Although PTPN11 is an oncogene, a reduction in the protein's function does not seem to increase skin cancer risk although there is concern over its link to leukaemia and, more recently, solitary granular cell tumours. ${ }^{4,5}$

This case demonstrates how taking a broad view of one's examination can ultimately reveal plentiful positive clinical signs. Furthermore, a keen eye and consideration of prompt genetic screening can result in unexpected diagnoses of rare genodermatosis and appropriate multidisciplinary management.

\section{References}

1 Gelb BD, Tartaglia M. Noonan syndrome with multiple lentigines. In: Pagon RA, Adam MP, Ardinger HH et al (eds). GeneReviews ${ }^{\circledR}$. Seattle: University of Washington, Seattle, 2007.

2 Martínez-Quintanaa E, Rodríguez-González F. LEOPARD syndrome: Clinical features and gene mutations. Mol Syndromol 2012;3:14557

3 Motegi S, Yokoyama Y, Ogino S et al. Pathogenesis of multiple lentigines in LEOPARD syndrome with PTPN11 gene mutation. Acta Derm Venereol 2015;95:978-84.

4 Zhang J, Zhang F, Niua R. Functions of Shp2 in cancer. J Cell Mol Med 2015;19:2075-83.

5 Hernández-Aragüés I, Campos-Domínguez M, Parra-Blanco V, Ezquieta-Zubicaray B, Suárez-Fernández R. LEOPARD syndrome and multiple granular cell tumors: An underreported association? Indian J Dermatol Venereol Leprol 2016;82:77-9.

Address for correspondence: Dr James WL Denny, Kingston Hospital NHS Foundation Trust, Galsworthy Rd, Kingston upon Thames KT2 7QB, UK.

Email: james.denny1@nhs.net 